\title{
Regulation - Do or Die: An Analysis of Factors Critical to New Product Development in a Regulatory Context
}

\author{
Clare O’Dwyer ${ }^{1}$, Kathryn Cormican ${ }^{1 *}$
}

\begin{abstract}
This study explores new product development in a strict regulatory and historically secretive environment. Adopting a systems perspective and a mixed methods approach in our research, we examine medical device development in Ireland. Findings indicate that the possession of a regulatory strategy expedites the rate of commercialization, so too does the generation of clear product definitions and marketing claims in the earliest developmental phases. Moreover, results suggest that if the regulated industry strengthens its culture for regulation by prioritizing regulation over speed to market, by encouraging cross-functional team collaborations, and by taking a more proactive approach in post-marketing surveillance activities, it has the potential to improve customer satisfaction and enhance product innovation. This study provides unique empirical data enriched by the homogeneity of its sample. It also contributes guidance to practitioners of new product development within a regulatory context.
\end{abstract}

Keywords: new product development; medical device development; innovation; technology innovation management; regulation management; regulatory culture; post-marketing surveillance.

Submitted: August 15 ${ }^{\text {th }} 2016 /$ Approved: February $23^{\text {th }} 2017$

\section{Introduction}

Unlike most other industries, strict regulatory oversight exists in the medical device industry primarily to mitigate against potential risks to human health. Regulation obliges medical device companies to prove efficacy and safe ty of heir products (Tobin \&Walsh, 2011), before being permitted market entry. Thus, for medical device companies, gaining and maintaining regulatory compliance is essential and synonymous with market access and ongoing trade viability but expensive, time-consuming and risky (Engberg \& Altmann, 2015). In today's fast-paced, dynamic and highly competitive marketplace, only companies able to innovate rapidly will survive (Collyer, Bakal, \& Verma, 2013). It is vital, therefore, that medical device companies learn how to manage regulatory and innovative demands simultaneously, for their sake and for the economies and patients they serve.

However, we find little direction exists to guide medical device companies on how to manage their regulatory obligations during new product development (NPD). Furthermore, of the regulatory information that does exist, Engberg and Altmann (2015) explain that "manufacturers often $h$ ave p roblems n avigating t he r egulatory t ext." Thus, while the extant literature is rich in prescriptive regulatory information (e.g. routes to regulatory compliance; how regulations impact innovation etc.), there is scant empirical evidence to support medical device companies in the management of regulation-bound technology innovation (Medina, Kremer, \& Wysk, 2013), despite the necessity of regulatory compliance to gain and maintain marketing approval. Additionally, the medical device industry is highly competitive and historically slow to share its modus operandi. Despite this, the medical device industry provides the ideal backdrop to explore new product development (NPD) in a strictly regulated environment to provide industry and context-specific data.
The overarching research goal, therefore, is to provide exploratory, context-rich, empirical data where currently it is lacking and fragmented. To this end, and we believe for the first time in the literature, we posed questions directly to stakeholders of medical device development (MDD), namely regulatory affairs, quality assurance, and marketing specialists about three, regulation-controlled, product development activities, crucial to MDD and concomitantly to the acquisition and ongoing retention of regulatory approval; 1. Defining the product 'intended use(s),' 2. Defining product 'marketing claims,' 3. Conducting 'post-marketing surveillance.' Furthermore, building upon the extensive body of literature in non-regulated new product development (NPD), we identified five recurring themes (Table 1), widely accepted as drivers of successful NPD, ('culture,' 'strategy for regulation,' 'commitment,' 'organisation of teams', and 'process') to examine their influence on medical device development (MDD). Preliminary interviews with experts in regulation and MDD, in conjunction with the literature, helped us to establish a framework (Table 2 ) that guided development of a 40 -item questionnaire.

Overall, we believe this study contributes valuable, new empirical insights that will help progress understanding and thus management of vital industries where increasing regulatory controls exist, and it provides practical guidelines for more efficient management of medical device innovations.

Since this research builds upon learnings from NPD research, an outline follows of the literature on five key themes driving NPD. We adapt these themes to the regulatory context of MDD to provide an explanation of our study framework. Next, we present the methodology, findings, and discuss our data analyses making recommendations for management. We conclude the paper with contributions.

1) College of Engineering and Informatics, National University of Ireland, Galway

*Corresponding author: kathryn.cormican@nuigalway.ie 


\section{Literature on New Product Development (NPD) and Themes of Success}

The extant literature in NPD covering over forty years' research, espouses five main themes drive successful NPD, namely "Process, Organization, Strategy, Commitment by senior management, and Cultu$r e$ " (Table 1). However, little empirical data exists that is particular to the medical device industry. We incorporate and adapt NPD themes to the regulatory context of medical device development (MDD) to explain our study framework, and review them next.

\subsection{The Process of new product development}

The NPD process refers to the strict set of activities beginning with an innovative idea (concept phase) and culminating in a new product for the market (commercialization) (Sun \& Wing, 2005). Khurana and Rosenthal (1998), describe the development process as a set of "distinct phases." De Waal and Knott (2010), advocate the existence of a "high quality, rigorous new product process" is "one of the strongest drivers of profitability." The significance of a well organised development process continues to be extolled (Cooper \& Kleinschmidt, 2007) and would be expected to apply equally to the regulated process of MDD (Collyer et al., 2013) as to the non-regulated process of NPD. Therefore, we investigated the MDD process.

Various models have been proposed but no consensus has yet been established. Models range from the simple (Holger, 2002), to the complex (Pietzsch, Shluzas, Paté-Cornell, Yock, \& Linehan, 2009). Based on the literature and our interviews with regulatory experts, we developed a simplified model (fig.1) which identifies six main phases to MDD. We used this model to target our questions to specific process phases to enhance the value of our findings.

Figure 1. The Process Phases of Medical Device Development

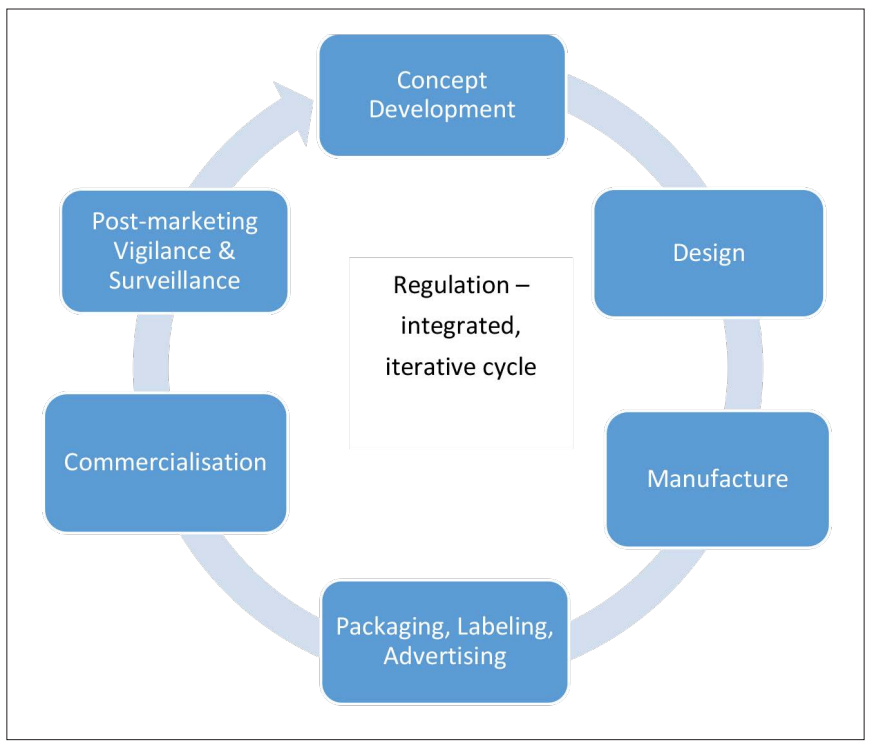

\subsubsection{Intended use(s) and Marketing Claims}

Two essential outputs of the heavily regulated MDD process are the product definitions of 'intended use(s)' (which describes the planned purpose(s) of the product), and 'marketing claims' (statements aimed at users in support of the product). These definitions are conceptualized, refined and defined during the process of MDD and come under regulatory scrutiny (Tobin \& Walsh, 2011).

A critical challenge for manufacturers of regulated goods is that to meet regulation's strict standards requires documented proof of product validity (product performs as it is planned to and for the purpose(s) it is intended) and product reliability (product performs consistently), (Tobin \& Walsh, 2011). Consequently, designing definitions of 'intended use(s)' requires great care, and assertions made by 'marketing claims' must correspond with those of 'intended use(s).' Since these product definitions come under such strict regulatory control, their management would be expected to impact regulatory approval and innovative outcomes, however, no empirical data for this exists. Moreover, once regulatory approval has been given for a stated purpose, any alterations to the product requires renewed approval by regulatory authorities. No data exists that measures the impact of such changes. In line with the literature in NPD, authors Fritz and Cardle (2012), Collyer et al. (2013), condone and indeed promote early phase definition of product characteristics, the earlier, the better for more efficient market access (Kumar \& Addie, 2006; Tobin \& Walsh, 2011). We examine these activities.

\subsubsection{Post-marketing surveillance}

A phase unique to that of regulated products is termed post-marketing surveillance (fig.1), which describes activities conducted after market entry for the regulatory obligation and purpose of providing evidence of on-going product safety and effectiveness in the marketplace (Tobin \& Walsh, 2011). Controversy exists in the literature. Some demand stricter regulatory controls enforcing the industry to proactively gather post-marketing feedback to help predict potential hazards by incidents such as the de Puy faulty hip joints scandal and other failures (Dhruva \& Redberg, 2012; Sorenson \& Drummond, 2014). Others argue that stricter regulation will impede innovation and delay patients gaining access to the newest and best treatment options (Gregory, Curfman, \& Redberg, 2011; Kierkegaard \& Kierkegaard, 2013). Kumar and Addie (2006) advise, customer feedback offers a powerful tool for measuring performance, "good and bad."

These facts offer a compelling argument for a closer examination of the MDD process paying particular attention to activities defining intended use(s), marketing claims, and post-marketing surveillance (Table 2).

\subsection{Organisation}

The theme of organization describes an "organizational setting within which the new product development process is active" (Cooper \& Kleinschmidt, 1995). It refers to teams of individuals who work together, led by an "empowered leader." Planning of the work is stressed, inter-team and cross-functional collaborations are encouraged (Sivasubramaniam, Liebowitz, \& Lackman, 2012). Kumar and Addie (2006), stress that "employee involvement and management 
attention ensured the ultimate success.” Morgan (2012), describes how inter-team collaborations build company capability. Thus, the body of knowledge conveys the criticality of employees within organizations and across teams being able to work well together so that companies can acquire and expand their capabilities to drive NPD.

In the medical device industry, the rapid development of new technologies incorporating complex entities has meant that, increasingly, cross-functional team collaborations are essential in their development (Hede, Nunes, Ferreira, \& Rocha, 2013). Individuals heretofore not used to working together, find themselves expected to co-operate and collaborate. The importance of good communication, trust in communication and opportunities for timely communications, are highlighted in the current literature. What is lacking are empirical data on relationships, communication, and levels of trust within and between teams involved in MDD. Our research seeks some of this data (Table 2).

\subsection{Strategy}

The literature is replete with references to the theme of strategy, a comprehensive review of which is beyond the scope of this paper. We conclude that a strategy for NPD describes a charter for NPD which directs the actions a company must take to achieve its goals for innovation and match its innovation capabilities (Cooper \& Kleinschmidt, 2007; Teece, 2008). Possession of a clear and formalized strategy links with successful NPD (De Waal \& Knott, 2010; Dodgson, Gann, \& Salter, 2008). It must be clearly communicated and understood by employees (Holger, 2002). A corporate strategy for NPD "states a welldefined role of NPD in the company's overall strategy" (Cooper \& Kleinschmidt, 2007), which makes the allocation of resources toward the strategy more likely (De Waal \& Knott, 2010).

Thus, we expect that the possession of a regulatory-strategy and one backed up in corporate strategy will support MDD. Our study tests for this in the medical device industry (Table 2).

\subsection{Commitment}

Cooper and Kleinschmidt (1995), describe senior management commitment as senior management's "involvement with and corporate commitment to new product development." Sun and Wing (2005) say it is when senior management "wholeheartedly" supports NPD and "visibly demonstrates this support" through clear communication, good employee relationships and the provision of resources toward NPD. Cooper and Kleinschmidt (1995), provide early evidence that making senior management accountable for NPD and tying in their incentives to successful outcomes, enhances NPD success.
Research indicates that the longer senior management holds responsibility for any project, the less likely they are to terminate that project (Jonas, 2010). On one hand, this could prove unhelpful if senior management becomes so deeply attached it fails to cull projects displaying signs of economic non-viability. On the other hand, senior management support can be powerful in holding off internal conflicts from negatively impacting the projects that they specifically back. A significant volume of literature exists which demonstrates that a lack of senior management support results in project failure (Easterby-Smith, Thorpe, \& Jackson, 2008). In our study, we examine the commitment shown by senior management toward regulation during MDD (Table 2).

\subsection{Culture}

Poolton and Barclay (1998) describe an innovation culture as one where "the will to innovate is enshrined in the corporate culture and forms the basis for innovation policies." It is considered essential in driving NPD success (Baker \& Sinkula, 2007). Senior management is expected to promote the company's innovative culture by providing a product "champion," supporting new ideas, encouraging creativity and rewarding risk taking, even if the outcome is failure (Rodriguez \& Hechanova, 2014).

Some authors say an integral element of an innovative culture is the active collection and distribution to staff of performance measurements (De Waal \& Knott, 2010; Kumar \& Addie, 2006). The theory is that employees who receive measures of performance become motivated to take personal responsibility for their contribution to performance (Morgan, 2012). We test for employees' knowledge of regulatory performance (Table 2).

A unique source of performance information is available to medical device companies through the activities of vigilance (responsive) and post-marketing surveillance (proactively sought) which provide direct customer feedback. Vigilance and post-marketing surveillance activities are also regulatory requisites in this industry. Feedback informs about users' real-life experiences and thus reflects customers' actual satisfaction or otherwise with the product in its market. This feedback can be very useful if it alerts an organization to a problem that could escalate to something more serious. Similarly, positive customer feedback could encourage and enhance further innovations. We test for a culture that supports regulation during MDD (Table 2). 
Table 1. Five themes associated with successful new product development and quotes.

\begin{tabular}{|c|c|c|}
\hline Theme & Best Practice Statements / Quotations & References \\
\hline Process & $\begin{array}{l}\text { Importance of a formal process } \\
\text { High quality, rigorous new product process } \\
\text { Importance of robust design } \\
\text { A clear concept of the future product \& its future markets }[\ldots] \text { early in the NPD process } \\
\text { A clear definition of the product before development begins }\end{array}$ & $\begin{array}{l}\text { Griffin 1997; Medina et al. } 2013 \\
\text { De Waal \& Knott } 2010 \\
\text { Zapata \& Cantu } 2008 \\
\text { Kumar \& Addie } 2006 \\
\text { Ika et al. } 2012 \\
\text { Salomo et al. 2010; Holger } 2002\end{array}$ \\
\hline Organisation & $\begin{array}{l}\text { Effective leaders/champions essential } \\
\text { Employee involvement \& management attention ensures success } \\
\text { Cross-functional issues are most important in the early stage of NPD } \\
\text { It is essential to engage team members in the planning process to ensure ownership of } \\
\text { the plan }\end{array}$ & $\begin{array}{l}\text { Griffin 1997; Lewrick } 2009 \\
\text { Kumar \& Addie } 2006 \\
\text { Sun and Win } 2005 \\
\text { Salomo et al. } 2010 \\
\text { Asgary \& Thamhain } 2016\end{array}$ \\
\hline Strategy & $\begin{array}{l}\text { Having a clear \& shared vision/charter } \\
\text { It is imperative to have clear \& specific strategies } \\
\text { A corporate strategy for NPD incorporates NPD into the company's overall strategy } \\
\text { Strategy determines the most appropriate process design \& complexity for the firm's } \\
\text { context \& targets } \\
\text { A formalized NPD strategy correlates with improved performance }\end{array}$ & $\begin{array}{l}\text { Griffin } 1997 \text { Lester } 1998 \\
\text { Cooper \& Kleinschmidt } 2010 \\
\text { Khang \& Moe } 2008 \\
\text { Lynn et al. } 1999 \\
\text { Dodgson et al. } 2008 \\
\text { De Waal \& Knott } 2010 \\
\end{array}$ \\
\hline Commitment & $\begin{array}{l}\text { Provision of top management attention } \\
\text { Provision of sufficient resources } \\
\text { Senior management commitment is key prerequisite for success } \\
\text { Commitment to quality is continually emphasized by senior management }\end{array}$ & $\begin{array}{l}\text { Griffin 1997; Lester 1998; Khang \& Moe } \\
\text { 2008; } \\
\text { Saloma et al. } 2010 \\
\text { Rodriguez \& Hechanova } 2014 \\
\text { Poolton \& Barclay } 1998 \\
\text { Kumar \& Addie } 2006 \\
\end{array}$ \\
\hline Culture & $\begin{array}{l}\text { An ethos that supports the entrepreneurial spirit } \\
\text { Rewards new ideas, permits risks to be taken } \\
\text { Encourages employee initiative } \\
\text { Knowledge of performance is essential } \\
\text { Management at all levels is accountable for achieving business, quality and compliance } \\
\text { success }\end{array}$ & $\begin{array}{l}\text { Cooper \& Kleinschmidt } 1995 \\
\text { Griffin 1997; Sun \& Wing } 2005 \\
\text { De Waal \& Knott } 2010 \\
\text { Ulrich \& Eppinger } 2008 \\
\text { George et al. } 2007\end{array}$ \\
\hline
\end{tabular}

\section{Method}

\subsection{Survey design and target population}

This exploratory study followed a two-phase, mixed-methods approach to data collection (Creswell, 2009; Dillman, 2007). During phase one, we conducted semi-structured interviews with regulatory specialists working in MDD, namely regulatory affairs and quality assurance. From these interviews, we identified constructs for the contents of our questionnaire (Table 2). Next, we pre-tested and piloted the questionnaire among eight individuals to confirm its validity and reliability (Fink, 2013).

In the second phase, we targeted a sample of 64 medical device companies based in Ireland (for homogeneity) and across all size categories, small (<50 employees), medium (51-249 employees) and large ( $>250$ employees), and involved in MDD and commercialization, thus necessitating regulatory approval. We sourced these companies through the Irish medical device association's membership directory (IMDA, 2016), supplemented with an on-line search of each organization. We excluded companies described as training business, software developer or supplier.

We dispatched 128 personalized requests for participation in the research, directing on-line questionnaires to the manager of two stakeholders' teams per company, namely, regulatory affairs and marketing. Employing best practice protocols (Saunders, 2012) to maximise response rate, we made a phone call to each of the 64 targeted companies requesting these managers' names, because, according to Sauermann and Roach (2013) "personalization increases the odds of responding by as much as $48 \%$." Through the process of snowballing or "response cascading" (Fink, 2013), we encouraged first contact respondents to ask their team colleagues to partake in the research. We assured anonymity, and to motivate completion of the relatively long questionnaire we interspersed long questions with short ones, added a 'progress bar' and offered a small prize from a draw to all participants completing the survey and willing to submit their contact details. We sent the survey using an on-line link which we left open for fourteen days. We followed up direct contacts with a reminder e-mail on day ten, and used statistical packages to analyze the data retrieved.

Since respondents were unknown to us, it guaranteed no "participant or observer bias response" (Saunders, 2012). Furthermore, because we presented respondents with an identical set of carefully selected questions, the questionnaire in the current study is deemed valid and reliable (Pallant, 2010).

\subsection{Questionnaire design}

We divided the questionnaire into seven categories (Table 2), five integral to the themes of our research, another to render sample background information (e.g. company size, years in role etc.), and one to collect various measures of performance. Some measures were inherent in the questionnaire by directly comparing responses to question sets (e.g. 'ideal' versus 'actual'). We requested other measures using empirical queries sourced mostly from De Waal and Knott (2010). 
Table 2. Themes to Construct and Questionnaire Development

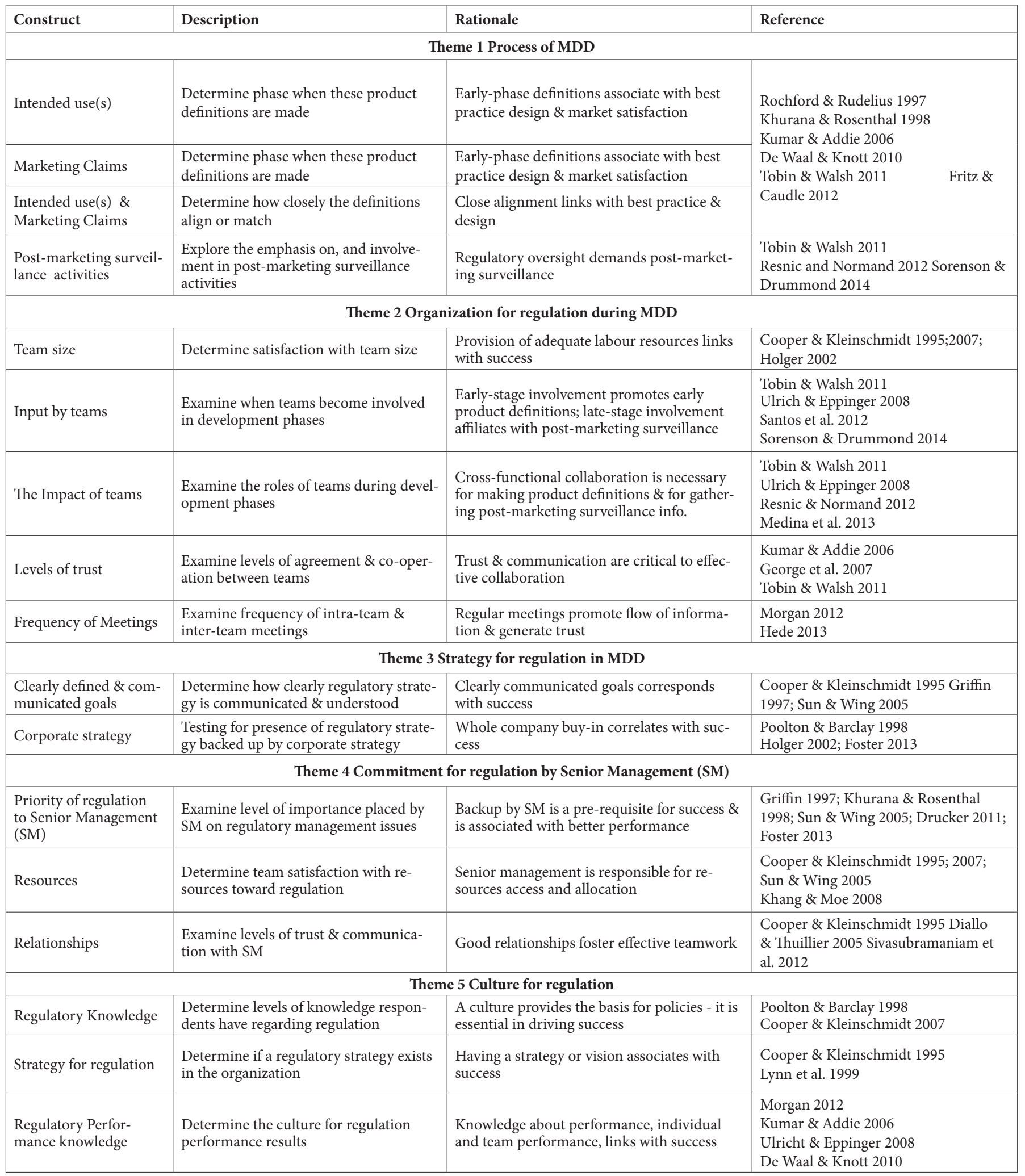




\begin{tabular}{|l|l|l|l|}
\hline \multicolumn{2}{|c|}{ Performance Measures } \\
\hline Construct & Description & Rationale & Reference \\
\hline $\begin{array}{l}\text { Questions related } \\
\text { to development } \\
\text { phase activities }\end{array}$ & $\begin{array}{l}\text { Identify actual vs. ideal phases for definition of intended use(s) } \\
\text { \& for definition of marketing claims } \\
\text { Assess actual vs. ideal level of alignment vs. } \\
\text { between intended use(s) \& marketing claims }\end{array}$ & $\begin{array}{l}\text { Knowledge of performance is linked to } \\
\text { success } \\
\text { Early definition is associated with good } \\
\text { practice } \\
\text { Close match is a prerequisite for regulato- } \\
\text { ry approval } \\
\text { Post-marketing surveillance contributes } \\
\text { to performance \& customer knowledge }\end{array}$ & $\begin{array}{l}\text { Poolton \& Barclay 1998 } \\
\text { Tobin \& Walsh 2011 } \\
\text { Resnic \& Normand 2012 }\end{array}$ \\
\hline $\begin{array}{l}\text { Questions seek- } \\
\text { ing empirical } \\
\text { measures of } \\
\text { performance }\end{array}$ & $\begin{array}{l}\text { Market approval rate within expected time interval } \\
\text { Rate market approval rejection/ delay } \\
\text { Number products submitted/approved for market approval in } \\
\text { previous year } \\
\text { Number new products commercialized in previous year } \\
\text { Percentage value of overall sales from newly approved products } \\
\text { in previous year }\end{array}$ & $\begin{array}{l}\text { Knowledge among employees of individ- } \\
\text { ual and company performance is linked } \\
\text { to ownership, motivation \& success }\end{array}$ & $\begin{array}{l}\text { Kumar \& Addie 2006 } \\
\text { de Waal \& Knott 2010 } \\
\text { Tobin \& Walsh 2011 } \\
\text { Morgan 2012 }\end{array}$ \\
\hline
\end{tabular}

\section{Results}

Our empirical findings identify some factors impacting MDD. At a granular level, we show that the earlier product definitions of intended use(s) and marketing claims are completed, and the better aligned they are with each other, the sooner regulatory approval and thus commercialization, are achieved. We find there is less emphasis on post-marketing surveillance than expected. We reveal insufficient engagement by marketing teams compared with regulatory affairs and quality assurance experts during early-phase, and late-phase MDD activities that impact regulatory approval rate, and we find that cross-functional team meetings are rare. At the holistic level, we demonstrate a significant correlation between possession of a strategy for regulation and 'speed to market', and that 'speed to market' is deemed the activity of greatest importance to senior management. Finally, we uncover a low level of tacit knowledge about a selection of regulation-specific performance measures.

\subsection{Sample demographics}

The survey was despatched directly to a purposefully targeted sample of 128 managers, 50\% in marketing and 50\% in regulatory affairs (or in charge of regulatory affairs duties). The overall response rate was $45 \%$ represented by 57 individuals from similar numbers of small $(<50 ; n=20)$, medium $(51-249 ; n=16)$ and large $(>250 ; n=21)$ medical device companies. Respondents included 14 marketing, 21 regulatory affairs and 22 quality assurance specialists, the vast majority of whom had over 11 years' experience in their specialty (fig.2).

Figure 2. Respondent Role and Company Size.

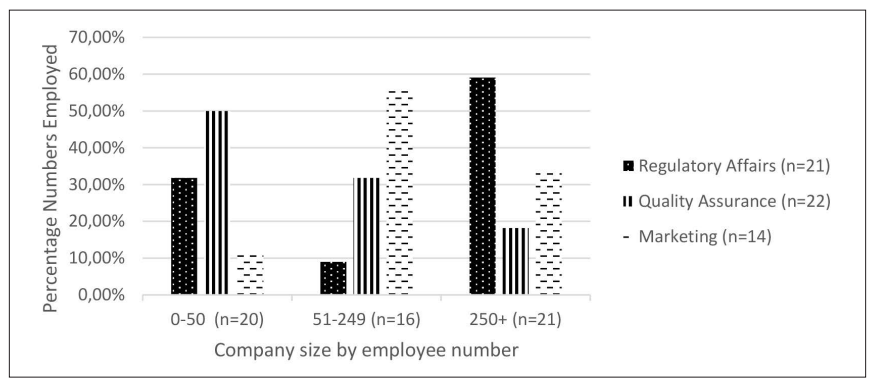

\subsection{The process of MDD}

Due to the relatively low number of marketing specialist respondents, and since most (except 3) dropped out after answering the early background questions, most of our analyses include responses from the 21 regulatory affairs and 22 quality assurance respondents.

\subsubsection{Intended use(s) definition}

Most specialists in both regulatory affairs and quality assurance (Table 3), recommend early phase confirmation of intended use(s) definitions, namely during concept development and design phases, with an emphasis by regulatory affairs specialists on confirming definitions during the first phase. However, in reality, intended use(s) definitions are often made during later developmental phases. A higher percentage of regulatory affairs (90\%) than quality assurance specialists (65\%) achieve intended use(s) definitions during the earliest development phases.

Table 3. Preferred timing and actual timing of product definition - intended use(s).

\begin{tabular}{|c|c|c|c|c|}
\hline \multicolumn{2}{|c|}{$\begin{array}{c}\text { Preferred timing of } \\
\text { intended use(s) } \\
\text { definition by specialty }\end{array}$} & \multirow{2}{*}{$\begin{array}{c}\text { Development } \\
\text { Phase }\end{array}$} & \multicolumn{2}{|c|}{$\begin{array}{c}\text { Actual timing of } \\
\text { intended use(s) } \\
\text { definition by specialty }\end{array}$} \\
\cline { 5 - 5 } $\begin{array}{c}\text { Regulato- } \\
\text { ry Affairs }\end{array}$ & $\begin{array}{c}\text { Quality } \\
\text { Assurance }\end{array}$ & & $\begin{array}{c}\text { Regulatory } \\
\text { Affairs }\end{array}$ & $\begin{array}{c}\text { Quality } \\
\text { Assurance }\end{array}$ \\
\hline $76 \%$ & $50 \%$ & $\begin{array}{c}\text { Concept } \\
\text { Development }\end{array}$ & $33 \%$ & $35 \%$ \\
\hline $24 \%$ & $45 \%$ & Design & $57 \%$ & $30 \%$ \\
\hline- & - & Manufacture & - & $5 \%$ \\
\hline- & - & $\begin{array}{c}\text { Packaging, Label- } \\
\text { ing, Advertising }\end{array}$ & $9.5 \%$ & $25 \%$ \\
\hline- & $2 \%$ & Commercialization & - & $5 \%$ \\
\hline
\end{tabular}

\subsubsection{Marketing claims definition}

The majority of respondents (Table 4) support early phase definition of marketing claims, with an emphasis by regulatory affairs specialists on achieving these definitions by the end of the design phase. In reality, marketing claims are often defined during later developmental phases. Again, a higher percentage of regulatory affairs (67\%) than quality assurance specialists (40\%) achieve earlier phase definitions. 
Table 4. Preferred timing and actual timing of product definitions marketing claims.

\begin{tabular}{|c|c|c|c|c|}
\hline \multicolumn{2}{|c|}{$\begin{array}{l}\text { Preferred timing of mar- } \\
\text { keting claims definition by } \\
\text { specialty }\end{array}$} & \multirow{2}{*}{$\begin{array}{c}\text { Development } \\
\text { Phase }\end{array}$} & \multicolumn{2}{|c|}{$\begin{array}{l}\text { Actual timing of market- } \\
\text { ing claims definition by } \\
\text { specialty }\end{array}$} \\
\hline $\begin{array}{c}\text { Regulatory } \\
\text { Affairs }\end{array}$ & $\begin{array}{c}\text { Quality } \\
\text { Assurance }\end{array}$ & & $\begin{array}{c}\text { Regulatory } \\
\text { Affairs }\end{array}$ & $\begin{array}{c}\text { Quality } \\
\text { Assurance }\end{array}$ \\
\hline $48 \%$ & $40 \%$ & $\begin{array}{c}\text { Concept } \\
\text { Development }\end{array}$ & $24 \%$ & $25 \%$ \\
\hline $48 \%$ & $30 \%$ & Design & $43 \%$ & $15 \%$ \\
\hline - & $5 \%$ & Manufacture & - & $10 \%$ \\
\hline- & $20 \%$ & $\begin{array}{l}\text { Packaging, } \\
\text { Labeling, Adver- } \\
\text { tising }\end{array}$ & $33 \%$ & $40 \%$ \\
\hline $2 \%$ & $5 \%$ & $\begin{array}{l}\text { Commercializa- } \\
\text { tion }\end{array}$ & - & $10 \%$ \\
\hline
\end{tabular}

A closer analysis reveals that in $29 \%$ of the smallest companies and in $35 \%$ of the largest companies, marketing claims are defined as late as during the phase of packaging, labeling, and advertising. Interestingly, $100 \%$ of marketing management respondents (though small in number) said that marketing claims should be defined by the end of the design phase at the latest.

4.2.3 Alignment between intended use(s) and marketing claims definitions The vast majority ( $81 \%$ ) of respondents believe that marketing claims and intended use(s) definitions should be 'very' closely aligned. More specifically, $95.2 \%$ of regulatory affairs specialists and $80 \%$ of quality assurance experts advocate preference for 'very' close alignment.

Figure 3 shows that the level of alignment achieved in reality, is not as close as experts deem preferable. Further analysis demonstrates that the closest alignments occur in the smallest and largest companies, which are also associated with the greatest proportion of regulatory affairs employees. Regulatory affairs respondents quote achievement of 'very close' alignment in $93.3 \%$ of cases, and only $6.7 \%$ report them to align 'somewhat closely.' By comparison, quality assurance specialists describe achieving 'very close' alignment in only $50 \%$ of cases.

\subsubsection{Impact of product definitions inaccuracies on rate of commercialization}

Respondents were asked about the delay caused to regulatory approval achievement, by different product definition inaccuracies (1-4 below). Pearson Chi-squared tests for correlations found associations of significance between "achieving clearance for market within the planned time-frame" (which is equivalent to achieving on-time regulatory approval) and each of the 4 product definition inaccuracies examined, namely;

1. unclear intended use(s) definition $(r=.476, \mathrm{~N}=41, p=.002)$,

2. missing data regarding intended use(s) definition $(r=.402$, $\mathrm{N}=42, p=.008$ ),

3. unclear marketing claims definition $(r=.410, \mathrm{~N}=40, p=.009)$,

4. missing data regarding marketing claims definition ( $r=.397$, $N=41, p=.010)$
All correlations were positive indicating that as the frequency of various inaccuracies increased, the frequency of gaining 'on-time approval' moved in the same direction from 'always' (1) to 'never'/'don't know' (4/5) i.e. ontime approval outcome decreases as delays are more regularly encountered.

Figure 3. Actual alignment between marketing claims and intended use(s).

\begin{tabular}{|c|c|}
\hline 19,10\% $66 \%$ & $\begin{array}{l}\because \text { Very close } \\
\text { - Moderately close } \\
\text { - Close } \\
\text { - Somewhat close } \\
\text { - Not close at all }\end{array}$ \\
\hline
\end{tabular}

\subsubsection{Post-marketing surveillance}

Table 5 shows that regulatory affairs and quality assurance teams are involved in post-marketing activities $93 \%$ of the time where they make an impact $70 \%$ of the time. In contrast, respondents reported that marketing teams are involved in post-marketing surveillance $47 \%$ of the time, making an impact only $40 \%$ of the time. Figure 4 indicates that, in only $18.8 \%$ of cases, senior management place a 'very high' level of importance on post-marketing surveillance activities.

\subsection{Organization for regulation during MDD}

\subsubsection{Engagement by teams - Involvement and Impact}

Regulatory affairs and quality assurance teams demonstrate a greater level of involvement and make a greater impact in all developmental phases, except product launch, compared with that of marketing teams (Table 5). Marketing teams are involved in the earliest phases of concept development and design, 54\% and 34\% of the time respectively, making an even smaller impact during those periods, $40 \%$ and 34\% respectively. Marketing teams' participation is highest during two development stages, product launch (82\%) and packaging, labeling and advertising (73\%), typically seen as marketing-specific responsibilities. The low levels involvement by marketing teams in post-marketing surveillance has already been highlighted.

Table 5. Involvement \& impact levels of teams during MDD.

\begin{tabular}{|c|c|c|c|c|}
\hline $\begin{array}{c}\text { Regulatory } \\
\text { Affairs \& } \\
\text { Quality As- } \\
\text { surance Teams }\end{array}$ & $\begin{array}{c}\text { Marketing } \\
\text { Team }\end{array}$ & $\begin{array}{c}\text { Phase of } \\
\text { Develop- } \\
\text { ment }\end{array}$ & $\begin{array}{c}\text { Regulatory } \\
\text { Affairs \& } \\
\text { Quality } \\
\text { Assurance } \\
\text { Teams }\end{array}$ & $\begin{array}{c}\text { Market- } \\
\text { ing Team }\end{array}$ \\
\hline Involvement & Involvement & $\begin{array}{c}\text { Concept } \\
\text { Impact }\end{array}$ & Impact \\
\hline $81 \%$ & $\mathbf{5 4 \%}$ & $\mathbf{4 3} \%$ & $\mathbf{4 0 \%}$ \\
\hline $91 \%$ & $\mathbf{3 9 \%}$ & $\begin{array}{c}\text { Design } \\
\text { Manufacture }\end{array}$ & $66 \%$ & $\mathbf{3 4 \%}$ \\
\hline $100 \%$ & $19 \%$ & $\begin{array}{c}\text { Packaging, } \\
\text { Labeling, } \\
\text { Commercial- } \\
\text { ization }\end{array}$ & $81 \%$ & $7 \%$ \\
\hline $98 \%$ & $82 \%$ & $\begin{array}{c}\text { Product } \\
\text { Launch }\end{array}$ & $45 \%$ & $85 \%$ \\
\hline $\mathbf{9 3 \%}$ & $\mathbf{4 7 \%}$ & $\begin{array}{c}\text { Post-mar- } \\
\text { keting sur- } \\
\text { veillance }\end{array}$ & $\mathbf{7 0 \%}$ & $\mathbf{4 0 \%}$ \\
\hline
\end{tabular}


4.3.2. Relationships, Trustworthiness, Communication and Meetings frequency

We examined the levels of trust and ease of communication felt by quality assurance and regulatory affairs respondents towards team colleagues and cross-functional team members. Respondents expressed lower levels of trust with marketing teams than with senior management or own team members. Communication with senior management showed a greater number who were 'satisfied', rather than 'very' or 'highly' satisfied. Few were 'highly' satisfied with communication between themselves and marketing teams.

Neither inter-disciplinary nor cross-functional team meetings are held frequently. Cross-functional team meetings take place once a week according to only $20 \%$ of quality assurance and $29 \%$ of regulatory affairs respondents. $14 \%$ of regulatory affairs respondents said they hold cross-functional team meetings every two weeks. $45 \%$ of quality assurance respondents report monthly cross-functional team meetings or even less frequent.

\subsection{Senior management support for regulation during MDD}

\subsubsection{Senior management emphasis of importance}

Figure 4 reveals respondents' perception of senior management priorities; its 'highest' level of importance attaches to achieving 'speed to market' (56.3\%), and its 'lowest' to 'post-marketing surveillance' (18.8\%). Furthermore, respondents reported that senior management attaches a 'high' to 'very high' level of importance on 'return of investment in marketing' (68.8\%). 79.1\% of respondents say senior management places a 'high' to 'very high' level of importance on 'meeting overall budgets.'

\subsubsection{Resource allocation by senior management}

Overall, respondents report a 'high level of satisfaction' (69.2\%) with 'team size, and with 'financial resources' (65.2\%), the greatest satisfaction is in the largest companies.

$80 \%$ of respondents who are 'dissatisfied' with team size and budgets are quality assurance specialists.

Figure 4. Senior management support per management activity.

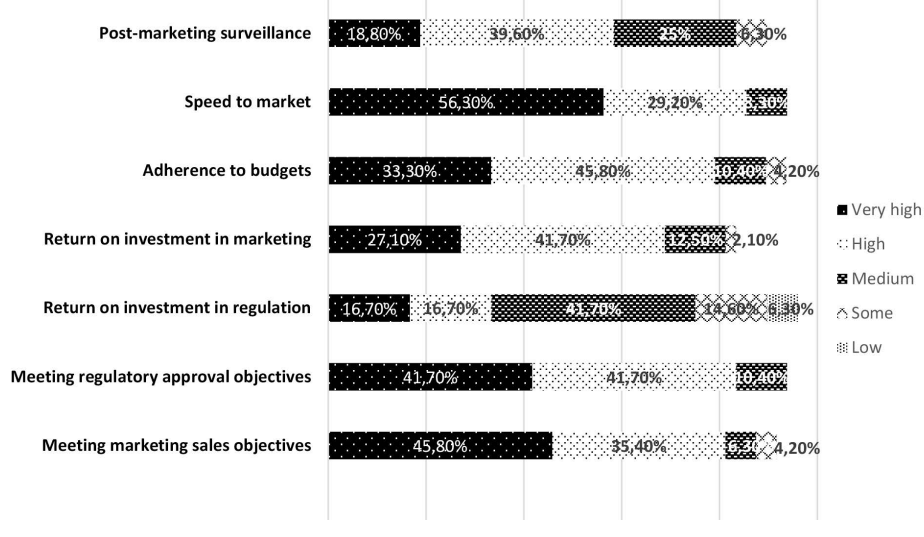

\subsubsection{Relationships with senior management}

A robust relationship appears to exist between senior management, regulatory affairs, and quality assurance respondents; 75\% describe senior management as 'very' or 'highly' 'supportive, and report overall 'level of trustworthiness' from 'good' to 'very high' in $93.5 \%$ of cases.

The study reveals lower 'levels of satisfaction' with 'communication between teams'. Only $23.9 \%$ of respondents are 'highly satisfied,' $28.2 \%$ are 'very satisfied.'

\subsection{Regulatory strategy findings}

The majority of respondent companies $(87 \%)$ possess a regulatory strategy. In $76 \%$ of these cases, the regulatory strategy is backed up by corporate strategy.

A Pearson's Chi-Squared test reveals a medium but significant negative correlation $\left(x^{2} / r=-.332, \mathrm{~N}=45, p=0.026\right)$, reflecting an increasing frequency of achieving on-time approval associated with possession of a regulatory strategy (variable scores for frequency of achievement go from 1 = always to $5=$ never, hence negative correlation). There is no association of significance between achieving on-time approval and having the regulatory strategy supported by corporate strategy. Further analysis shows that possession of a regulatory strategy is more likely in larger companies.

Most respondents report that regulatory strategy goals are clear and well communicated to them. $56 \%$ of respondents declare regulatory objectives are 'very clear', $28 \%$ claim they are 'moderately clear' and of these, $40 \%$ work in quality assurance.

\subsection{Regulatory culture findings}

\subsubsection{Regulatory knowledge}

Not surprisingly, the study shows that regulatory affairs specialists have the highest level of knowledge on regulatory matters. 95\% say their 'regulatory knowledge' is 'very good' or 'expert.'

Only $10 \%$ of quality assurance experts report an 'expert' level of regulatory knowledge, $45 \%$ say their regulatory knowledge is 'very good, $40 \%$ call it 'good.'

None of the marketing personnel report an 'expert' level of regulatory knowledge.

In order of 'impact', respondents reported that regulation has its 'largest impact' on 'safety' and 'quality' followed by 'reliability, 'effectiveness,' 'speed to market,' and interestingly, they see regulation having its 'least impact' on product 'cost.' However, a notable finding is that only $27.3 \%$ consider that regulation has its 'greatest impact' or its 'second greatest impact' on 'speed to market.'

\subsubsection{Regulation-related performance results}

Many respondents were unable to comment on the different performance related queries posed, and the more empirical the questions, the higher the percent of 'don't know' responses. Examples below; On average, do new products attain market approval within the expected time-frame? 'Don't know' (17\%) 
On average, how many products were submitted for market approval in the last year? 'Don't know' (39\%)

On average, how many products were approved in the last year? 'Don't know' (41\%)

On average, how many newly-approved products were commercialized in the last year? 'Don't know' (52\%)

What was the average percent value of overall sales contributed by newly approved products in the last year? 'Don't know' (83\%).

Even when presented with some reasons (5) that might cause regulatory approval rejection or even delay, a third of respondents in regulatory affairs and quality assurance could not say how frequently rejection resulted. On average, 55\% could not even give an average length of delay in months.

\section{Discussion}

Operating within a strict regulatory context means that regulated industries face an everyday struggle with competing demands. On the one hand, a market that expects rapid innovation to provide its customers with the newest technology at best price. On the other hand, regulatory oversight insists on precious and costly time investment to provide documented proof of product validity, efficacy, and safety, to gain permission to launch into and remain in the market. This conflict between the need to reach markets faster than the competition while simultaneously devoting adequate time to acquire and maintain regulatory compliance status, is an on-going yet critical challenge faced uniquely by regulation-controlled industry, and one not yet adequately addressed in the literature. Our study provides badly needed empiric insights into NPD in one highly regulated industry, the medical device industry in Ireland. Thus, we provide a more detailed picture of the realities of innovation within a regulatory context and add to the body of awareness about MDD in Ireland, to assist the industry in managing MDD.

\subsection{Sample demographics}

The medical device industry is a difficult one from which to extract information, we are very satisfied with a response rate of $45 \%$ (57 respondents).

The study achieves a good balance in all company sizes (large, medium, small), and of regulatory affairs and quality assurance specialists. As a result, the study reveals some trends associated with company size and some associated with the respondents' role. Moreover, since our respondent companies are all located in Ireland, we have a homogenous sample providing context-specific data. As such, we can make comparisons between companies since all are operating within the same economic and political environment. Also, our respondents have more than eleven years' experience in their respective specialty making their responses more likely valid, e.g., Cooper and Kleinschmidt (1995) only accepted respondents into their research who had a minimum of 3 years' experience.

\subsection{Activities associated with the process of MDD}

The activities of defining product use(s) and marketing claims are process development activities within MDD that are central to creating and selling a new product's identity. These activities are also critically analyzed as part of regulatory oversight. The activities of postmarketing surveillance are a prerequisite of continued regulatory satisfaction, and the feedback produced has the potential to add to a company's body of information on its customers and its products. Consequently, gaining deeper insight into these three regulation-controlled process activities was pivotal in our research.

\subsubsection{Intended use(s) and Marketing claims}

In agreement with the literature that associates early phase product definitions with more successful NPD (Cooper \& Kleinschmidt, 2007; De Waal \& Knott, 2010), our research supports a more closely integrated process for MDD.

First, we find significant agreement among specialists that intended use(s) and marketing claims definitions should be confirmed preferably during the first and no later than the second phase of the MDD process. These respondents who are important stakeholders in regulation, agree with a high degree of alignment between intended use(s) definitions and marketing claims. However, our findings show that in the real world, product definitions are often incomplete after early process phases, and there is less alignment between definitions than respondents deem preferable. Further analysis of findings indicates that inadequacies in the clarity of these product definitions ('unclear definitions') and in their completeness ('missing data'), extend the time-frame for the achievement of regulatory approval and thus of market commercialization.

Khang and Moe (2008), advise on "the impact early phases have on later stages." Like dominoes, the effect of tardiness in one step affects the next, several mini changes can accumulate to lead to a sizeable deviation by completion of all development stages. We suggest that delays in completing medical device product definitions and poor alignment between them, negatively impact MDD outcome.

Study findings show that regulatory affairs respondents most strongly advocate and achieve early phase definitions of, and a very close alignment between, intended use(s) and marketing claims descriptions, compared with other respondent roles. This must have implications on regulatory approval timelines. In our research, a regulatory affairs expert with fourteen years' experience contends that "intended use(s) definitions must be made during concept development because product design depends on the intended use(s)." The expert adds "this is commonly misinterpreted but the whole design and testing should be based on what the intended uses are as well as the design - you can have identical designs with different classifications based on your intended use - very few engineers get this." This emphasizes the significance of clear product definitions. Thus, we posit that regulatory affairs specialists are best placed to promote optimal regulation-controlled product definitions outcomes, during MDD. 
It is well-accepted that making alterations to product definitions becomes increasingly expensive as product development proceeds (Collyer et al., 2013; Fritz \& Cardle, 2012). Thus, we suggest that our findings have implications for improved MDD, directing companies to specify and align intended use(s) and marketing claims definitions early, clearly and in full, to drive more successful MDD.

It is noteworthy that the smallest teams of regulatory affairs specialists are associated with medium-sized companies (fig.2). Perhaps quality assurance respondents in medium-sized companies are expected to conduct regulatory as well as quality assurance functions (Tobin \& Walsh, 2011). Thus, quality assurance respondents may be overburdened which might explain the aforementioned trend for less alignment and later achievement of product definitions associated with the quality assurance role and medium-sized companies.

\subsubsection{Post-marketing surveillance}

As explained elsewhere in this paper, the requirement for the medical device industry to monitor the performance of its marketed products is obligatory. The reason is to satisfy regulatory authorities that the medical devices remain useful and safe in the community where far greater numbers of people access and use them compared with limited users during clinical trials. As such, the industry might be expected to a) place a high priority on conducting post-marketing surveillance and b) encourage the active participation of teams involved in regulation and customer contact, in gathering post-marketing feedback.

Contrary to expectations, we find that a) senior management attaches a 'very high' level of importance to post-marketing surveillance activities in less than $20 \%$ of cases. Instead, 'speed to market' is senior management's leading priority. The emphasis on post-marketing surveillance comes only $6^{\text {th }}$ place in priority, and b) while marketing teams are best placed to gather post-marketing feedback because of their frequent and on-going direct contact with customers and users, they demonstrate a disappointing less than 50\% involvement in the activity.

We suggest this is a missed opportunity for the industry. First, we recommend that the industry should regard post-marketing surveillance more highly and conduct it more proactively so that potential problems become identified when they are on a small scale. In so doing, it could prevent the type of large-scale scandals mentioned earlier which not only jeopardize peoples' health but also negatively impact a company's reputation that can take years to rebuild. Secondly, such scandals have led to increasing calls for increased regulation of the industry to pre-empt such disasters (Kierkegaard \& Kierkegaard, 2013). By taking a more proactive role in post-marketing surveillance, the industry could increase its control over the management of safety issues and ameliorate calls for greater regulatory oversight. Moreover, it could provide useful information to MDD teams to feed into future product improvement and innovation plans.

Finally, by placing 'speed to market' and 'return on marketing budgets' at higher priority levels than the pursuit of 'post-marketing activities,' senior management may be inadvertently creating conflict between marketing teams and regulatory affairs/quality assurance teams. Since the future of medical device innovation calls for increasing cross-functional collaborations (Hede et al., 2013), this issue needs further examination. After all, improving rates of regulatory approval will contribute to greater speed to market!

\subsection{Teams and MDD}

The research asked respondents during which phases in the MDD process do their respective teams become involved, and, arguably more importantly, how influential they believe their input is. Unexpectedly, we found that in approximately half of cases, marketing teams are not involved in the concept development phase while in even more cases, they are not involved in the design phase. The literature contends "it is shown that, in particular, the preparatory work [...] in the early phases of the NPD process [...] are decisive for the success of new products" (Holger, 2002), which begs the question how organizations expect to make clear, unambiguous and timely product definitions if the experts who are expected to market these products are not present to provide input and have an impact on product definition decisions. Indeed, $100 \%$ of marketing management respondents concur that marketing claims should be defined by the end of the design phase at the latest, which further highlights the questionable absence of marketing teams in a substantial number of cases, during early NPD phases.

We examined the relationships, levels of trust and communication between cross-functional teams and enquired about the frequency of team meetings. In some cases, findings showed low levels of trust, lower levels of communication and infrequent cross-functional team meetings. These findings may explain our discovery of less collaboration than expected between teams during the earliest and latest process phases. It may reflect the tensions we surmise exists between marketing teams and regulatory affairs/quality assurance teams due to senior management's emphasis on 'speed to market' over 'achievement of regulatory approval.' If emphasis is placed on improved collaboration between teams, it could foster improved relationships, engender higher levels of trust and enhance communication within and between teams, and drive earlier phase product definitions and later phase post-marketing surveillance activities, improving MDD (Cooper \& Kleinschmidt, 2007).

\subsection{Senior management support for regulation}

The literature advocates that commitment by senior management to innovation enhances NPD. We advocate that commitment by senior management to regulation will enhance MDD. We propose that senior management should exhibit this commitment to regulation in the same way it does to innovation. In summary, senior management should continually and consistently support regulatory authorities' requirements by emphasizing the priority and value of regulatory compliance to employees ahead of the expedition of products to market. Senior management should provide adequate resources to support regulatory goals, and develop excellent relations with employees who manage regulation issues.

Findings reveal that respondents are, in the main, satisfied with resources toward regulation provided by senior management and that the best relationships of trust and communication exist between respondent teams and senior management. This bodes well for regulatory management. 
However, lower levels of both trust and communication appear evident between regulatory affairs/quality assurance teams and marketing teams. We have seen that 'speed to market' is perceived by our respondents to be the highest priority of senior management. Thus, achieving regulatory approval including support for post-marketing surveillance activities, competes with senior managements' desire to reach the markets quickly. Gaining market access is seen as a responsibility of marketing teams and may explain the poorer relationship and levels of trust we find between marketing teams and the other respondent teams. Marketing may feel that regulation holds back progression towards markets. Such findings may indicate that a gap exists in the knowledge of senior management about the interdependence between achieving regulatory approval and timely market access. We suggest senior management raises the priority level of 'achieving regulatory approval' ahead of achieving 'speed to market' and encourages stronger alliances and co-operation between marketing, regulatory and quality assurance teams to expedite both regulatory approval rates and consequently commercialization.

Furthermore, the relatively low emphasis placed on post-marketing surveillance by senior management suggests a low appreciation for the potential contribution toward improved product development that is inherent in such feedback. A greater emphasis on post-marketing surveillance should drive product innovation and overall customer satisfaction.

\subsection{Strategy for regulation}

Most of the companies in our research sample purport to have a regulatory strategy and of these, three- quarters say that it also forms part of corporate strategy. Our findings show that where a regulatory strategy exists, most respondents believe it is clear and well communicated. The study shows no findings of statistical significance between company size and the possession of a regulatory strategy. However, there is a statistically significant correlation in the association between having a regulatory strategy and achieving on-time approval more frequently which leads us to recommend that all companies should strive to ensure a clear, well-communicated regulatory strategy exists in their organization. According to the literature in NPD, integration of the strategy within the corporate strategy can only further advance successful MDD.

\subsection{A culture for regulation}

It is no surprise that regulatory affairs specialists possess the greatest levels of knowledge on the subject of regulation. What is surprising is that only $45 \%$ of quality assurance respondents deem their regulatory knowledge to be "very good" and as many as 30\% of marketing respondents report their knowledge at the lowest level. These findings suggest a disadvantage for companies in which the regulatory affairs position does not exist and where quality assurance personnel carry out regulatory and quality duties. The importance of and distinction between each of these separate roles is illustrated by Fritz and Cardle (2012), who say "Regulatory Affairs deals mostly with issues related to compliance. Quality Assurance encompasses the processes, procedures, and culture that permeate an organization - enabling it to consistently develop and produce high-quality [...] products that will meet or exceed regulatory requirements." In our study, while we cannot be sure that quality assurance respondents did not work alongside regulatory affairs colleagues in their respective organization, it seems unlikely. During survey dispatch, we requested the identity of regulatory affairs personnel. If we received information saying the regulatory affairs role was non-existent, we were advised that someone in quality assurance was in charge of regulatory affairs duties. Nevertheless, our results suggest a greater knowledge capacity for regulation in the largest companies where regulatory affairs teams are at their biggest. In organizations where quality assurance employees have direct and sole responsibility for maintaining regulatory compliance and quality assurance, these specialists may be under significant work-pressure. This may explain our findings of greater levels of dissatisfaction among quality assurance respondents regarding regulation-related resources provided to them, team sizes, and the lower regulatory compliance performance seen associated with quality assurance versus regulatory affairs specialists.

We cite a lower level of regulatory knowledge among marketing respondents. Perhaps this reflects a gap in knowledge of the value marketing teams could offer NPD, and perhaps it explains the absence of marketing teams during concept and design development phases in a high number of cases, which a stronger culture for regulation could help redress.

Interestingly, we reveal a low level of respondent knowledge regarding regulatory-related performance data; the extant literature advises that employees should have knowledge of performance results to improve their performance. We suggest that MDD would benefit from greater stakeholder knowledge of regulatory performance outcome measures.

The knowledge amongst respondents that regulation impacts a product's safety and reliability, appears to be well communicated to respondent. This finding reflects a culture that associates regulation with good practice. It is interesting that only $27.3 \%$ consider that regulation has its "greatest impact" or its "second greatest impact" on 'speed to market.' This finding suggests that respondents do not feel that regulation hinders speed of market access. However, it may also suggest that the majority of respondents are ignorant of the direct connection between acquisition of regulatory approval and market access. In other words, stakeholders may not fully appreciate that if regulatory approval is achieved efficiently through a wholehearted company approach and employee commitment toward regulation, it will positively influence the speed of market access. This finding may be the most significant one of our study.

Consequently, a culture that would encourage embracing regulation has the potential to improve outcomes of all the measures in our study. A culture of regulation would insist on a number of conditions; first, a strategy for regulation supported by the corporate strategy; second, senior management displaying very strong commitment to regulation including promotion of regulatory knowledge training, dissemination of regulatory performance data to employees and encouragement of high levels of communication on regulatory matters; third, teams fostering cross-functional collaborations including 
marketing teams' involvement during earlier product development phases to confirm product definitions and drive closer alignment of definitions leading to more rapid commercialization. Furthermore, a stronger culture for regulation would encourage marketing teams, in particular, to take a more proactive approach in gathering postmarketing surveillance information that would improve compliance and could advance improved medical device innovation outcomes. As Medina et al. (2013) explain, "the regulatory requirements [...] play a substantive role in shaping activities and decisions in the [development] process." Consequently, regulatory requirements must always be at the forefront of all considerations regarding MDD.

\section{Conclusions and Recommendations}

Regulatory strategies are built around the classification of devices according to risk, so, as medical devices become increasingly elaborate and complex, regulatory strategy demands will grow (Holger, 2002; Tobin \& Walsh, 2011). Tensions between NPD and regulatory compliance are therefore likely to become increasingly salient in MDD. Also, new collaborations will grow between multidisciplinary teams and will require nurturing because of divergent and competing objectives. This is a highly complicated scenario that companies must learn to navigate to enable timely market entry and organizational survival.

Our findings expose serious gaps in the management of medical device innovation. We emphasise the need for management within the industry to put a stronger emphasis on regulatory management over speed to market; incorporate regulatory strategy into the corporate agenda; encourage improved relationships and collaborations between multidisciplinary teams during MDD, particularly in the earliest process phases of development when product definitions are being determined; actively gather and share post-marketing feedback; and encourage knowledge of regulatory performance amongst key stakeholders; all to enable more effective and efficient MDD within its regulatory framework.

If our work exposes nothing more than the direct influence regulatory management has upon the speed at which new medical devices can enter and continue to thrive in their markets, it will have been worthwhile. We conclude by recommending that the medical device industry adopts an organizational culture for regulation by "embracing regulation" throughout all MDD activities.

\section{Contribution}

This research is significant first because it is built on real world empirical data and to our knowledge no comparable data exists; we believe our study within the medical device industry based in Ireland is the first and largest of its kind. Given the size and significance of this industry in Ireland and globally, this in itself makes our contribution meaningful. Our work contributes to the study and practice of MDD. It identifies factors associated with expediting MDD and exposes key issues requiring further research into the management MDD. Overall, it expands our knowledge and deepens our understanding in an area of mutual benefit to our economy, the medical device industry, medical professionals and the public at large.

\section{References}

Baker, W. E., \& Sinkula, J. M. (2007). Does Market Orientation Facilitate Balanced Innovation Programs? An Organizational Learning Perspective. Journal of Product Innovation Management, 24(4), 316334. doi:10.1111/j.1540-5885.2007.00254.x

Collyer, K., Bakal, M. R., \& Verma, P. (2013). Three steps to rapid development of high-quality medical devices within regulatory norms.

Cooper, R. G., \& Kleinschmidt, E. J. (1995). Benchmarking the firm's critical success factors in new product development. Journal of Product Innovation Management, 12(5), 374-391. doi:http://dx.doi. org/10.1016/0737-6782(95)00059-3

Cooper, R. G., \& Kleinschmidt, E. J. (2007). Winning businesses in product development: The critical success factors. Research Technology Management, 50(3), 52-66.

Creswell, J. W. (2009). Editorial: Mapping the Field of Mixed Methods Research (Vol. 3, pp. 95-108).

De Waal, G. A., \& Knott, P. (2010). Process and strategy influences on product development performance in New Zealand. Small Enterprise Research, 17(2), 193-206. doi:10.5172/ser.17.2.193

Dhruva, S. S., \& Redberg, R. F. (2012). Medical Device Regulation: Time to Improve Performance. PLoS Medicine, 9(7), 1-2. doi:10.1371/ journal.pmed.1001277

Dillman, D. A. (2007). Mail and internet surveys : the tailored design method (2nd, 2007 update with new internet, visual, and mixed-mode guide. ed.). Hoboken, N.J.: Hoboken, N.J. : Wiley.

Dodgson, M., Gann, D., \& Salter, A. (2008). The management of technological innovation : strategy and practice (New ed., rev. and updated. ed.). Oxford New York: Oxford New York : Oxford University Press.

Easterby-Smith, M., Thorpe, R., \& Jackson, P. (2008). Management research (3rd ed.). Los Angeles. London: Los Angeles. London : SAGE.

Engberg, R., \& Altmann, P. (2015). Regulation and Technology Innovation: A Comparison of Stated and Formal Regulatory Barriers throughout the Technology Innovation Process. Journal of Technology Management \& Innovation, 10(3), 85-91.

Fink, A. (2013). How to conduct surveys : a step-by-step guide (5th ed.). Thousand Oaks, Calif.: Thousand Oaks, Calif. : SAGE Publications.

Fritz, M., \& Cardle, A. (2012). The foundations of pharmaceutical compliance for beginners. (3639). Retrieved May 2016, from Pharmaceutical Compliance Monitor http:/www.pharmaceuticalcompliancemonitor.com/the_foundations_of_pharmaceutical_compliance_for_ beginners/3639/accessedMay2016

Gregory, D., Curfman, G. D., \& Redberg, R. F. (2011). Medical devices--balancing regulation and innovation. New England Journal of Medicine, 365(11), 975-977. 
Hede, S., Nunes, M. J. L., Ferreira, P. F. V., \& Rocha, L. A. (2013). Incorporating sustainability in decision-making for medical device development. Technology in Society, 35(4), 276-293. doi:http://dx.doi. org/10.1016/j.techsoc.2013.09.003

Holger, E. (2002). Success Factors of New Product Development: A Review of the Empirical Literature. International Journal of Management Reviews, 4(1), 1.

IMDA. (2016). Irish Medical Devices Association Membership Directory. Retrieved from http://www.imda.ie/Sectors/IMDA/IMDA. nsf/vPages/Membership membership-directory!OpenDocument

Jonas, D. (2010). Empowering project portfolio managers: How management involvement impacts project portfolio management performance. International Journal of Project Management, 28(8), 818831. doi:10.1016/j.ijproman.2010.07.002

Khang, D. B., \& Moe, T. L. (2008). Success criteria and factors for international development projects: A life-cycle-based framework. Project Management Journal, 39(1), 72-84. doi:10.1002/pmj.20034

Khurana, A., \& Rosenthal, S. R. (1998). Towards Holistic "Front Ends" In New Product Development. Journal of Product Innovation Management, 15(1), 57-74. doi:10.1111/1540-5885.1510057

Kierkegaard, S., \& Kierkegaard, P. (2013). Danger to public health: Medical devices, toxicity, virus and fraud. Computer Law and Security Review: The International Journal of Technology and Practice. doi:10.1016/j.clsr.2012.11.006

Kumar, S., \& Addie, H. S. (2006). The Hexopater TM , from birth to market: innovative product development challenges. Journal of Engineering Design, 17(3), 271-289. doi:10.1080/09544820500274282

Medina, L. A., Kremer, G. E. O., \& Wysk, R. A. (2013). Supporting medical device development: a standard product design process model. Journal of Engineering Design, 24(2), 83-119. doi:10.1080/095448 28.2012.676635

Morgan, N. (2012). Marketing and business performance. Official Publication of the Academy of Marketing Science, 40(1), 102-119. doi:10.1007/s11747-011-0279-9
Pallant, J. (2010). SPSS survival manual a step by step guide to data analysis using SPSS (4th ed.). Maidenhead [etc.]: Maidenhead : Open University Press/McGraw-Hill.

Pietzsch, J. B., Shluzas, L. A., Paté-Cornell, M. E., Yock, P. G., \& Linehan, J. H. (2009). Stage-Gate Process for the Development of Medical Devices. Journal of Medical Devices, 3(2), 021004. doi:10.1115/1.3148836

Poolton, J., \& Barclay, I. (1998). New Product Development From Past Research to Future Applications. Industrial Marketing Management, 27(3), 197-212. doi:http://dx.doi.org/10.1016/S0019-8501(97)00047-3

Rodriguez, R. P., \& Hechanova, M. R. M. (2014). A Study of Culture Dimensions, Organizational Ambidexterity, and Perceived Innovation in Teams. Journal of Technology Management \& Innovation, 9(3), 21-33.

Sauermann, H., \& Roach, M. (2013). Increasing web survey response rates in innovation research: An experimental study of static and dynamic contact design features. Research Policy, 42(1), 273-286. doi:10.1016/j.respol.2012.05.003

Saunders, M. (2012). Research methods for business students (6th ed. ed.). Harlow, England ; New York: Harlow : Pearson.

Sivasubramaniam, N., Liebowitz, S. J., \& Lackman, C. L. (2012). Determinants of New Product Development Team Performance: A Meta-analytic Review. Journal of Product Innovation Management, 29(5), 803-820. doi:10.1111/j.1540-5885.2012.00940.x

Sorenson, C., \& Drummond, M. (2014). Improving Medical Device Regulation: The United States and Europe in Perspective. Milbank Quarterly, 92(1), 114-150. doi:10.1111/1468-0009.12043

Sun, H., \& Wing, W. C. (2005). Critical success factors for new product development in the Hong Kong toy industry. Technovation, 25(3), 293-303. doi:10.1016/S0166-4972(03)00097-X

Teece, D. J. (2008). Technological know-how, organizational capabilities, and strategic management : business strategy and enterprise development in competitive environments. New Jersey: New Jersey: World Scientific.

Tobin, J. J., \& Walsh, G. (2011). Medical Product Regulatory Affairs: Pharmaceuticals, Diagnostics, Medical Devices (2nd ed.): Wiley. 